\title{
ELECCIÓN DE LOS DIPUTADOS TERRITORIALES DE MINERÍA: UNA MIRADA A TRAVÉS DE SUS EXPEDIENTES
}

\author{
ELECTION OF THE TERRITORIAL DEPUTIES OF \\ MINING: A GLANCE THROUGH ITS FILES
}

GIOVANNA VALENCIA ÁLVAREZ

Escuela Nacional de Archiveros

Resumen: El interés del presente artículo, no es realizar un estudio crítico de la minería peruana en sus diferentes etapas históricas, lo que busca es acercarlos al desarrollo de su administración a través del proceso de elección de los "Diputados Territoriales", quienes representaron a los mineros o dueños de minas de acuerdo a lo que estipulaban las Ordenanzas que se promulgaron en el Perú mediante una Real Orden dada por Carlos III en 1785. En una primera parte se examinará los dispositivos legales que normaron la minería peruana antes de la instalación del Tribunal, poniendo énfasis en las autoridades que participaron o intervinieron en la regulación de las "empresas” mineras, para avanzar hasta finales del siglo XVIII cuando se adaptaron las Ordenanzas, dictadas para el territorio de Nueva España, al virreinato peruano mediante las Declaraciones del Superintendente de la Real Hacienda Jorge de Escobedo y finalizar el proceso de elección de los diputados a través de sus expedientes mediante el uso de las herramientas diplomáticas.

Palabras clave: Minería peruana, Diputados territoriales, Ordenanzas, Carlos III, Nueva España, Superintendente de la Real Hacienda, Jorge de Escobedo.

Abstract: The interest of the present article, is not to make a critical study of the Peruvian mining in its different historical stages, which looks for is to approach them the development of its administration through process of election of the "Territorial Deputies", who represented the miners or owners of mines according to which they stipulated the Decrees that were promulgated in Peru by means of a Real Order issued by Carlos III in 1785. In one first part it will be examined the legal devices that normaron the Peruvian mining before the installation of the Court, putting emphasis in the authorities which they participated or they took part in the regulation of the "mining companies", to advance until end of century XVIII when the Decrees adapted, dictated for the territory of the New Spain, to the Peruvian virreinato by means of the Declarations of the Superintendent of the Real Property Jorge of Escobedo and to finalize the process of election of the deputies through its files by means of the use of the diplomatic tools.

Keywords: Peruvian mining, Territorial Deputies, Decrees, Carlos III, New Spain, Superintendent of the Real Property, Jorge de Escobedo. 
El tema de la minería colonial peruana ha sido objeto de innumerables investigaciones a lo largo de la historia inclusive desde la perspectiva de los mismos actores de esta actividad económica que de no haber tenido tanta importancia para Europa no hubiese generado tanto entusiasmo.

La extracción de los metales preciosos tuvo como consecuencia no sólo el uso de la moneda como herramienta de intercambio para la adquisición de las diferentes mercaderías o el surgimiento de nuevos grupos sociales como producto de esta labor tan fructífera sino que también fue indispensable el establecimiento de una administración encargada de poner en práctica las disposiciones en torno a la minería como lo será casi a finales del siglo XVIII el Tribunal de Minería.

El interés del presente artículo, no es realizar un estudio crítico de la minería peruana en sus diferentes etapas históricas, lo que busca es acercarlos al desarrollo de su administración a través del proceso de elección de los "Diputados Territoriales”, quienes representaron a los mineros o dueños de minas de acuerdo a lo que estipulaban las Ordenanzas que se promulgaron en el Perú mediante una Real Orden dada por Carlos III en 1785.

En una primera parte se examinará los dispositivos legales que normaron la minería peruana antes de la instalación del Tribunal, poniendo énfasis en las autoridades que participaron o intervinieron en la regulación de las “empresas” mineras, para avanzar hasta finales del siglo XVIII cuando se adaptaron las Ordenanzas, dictadas para el territorio de Nueva España, al virreinato peruano mediante las Declaraciones del Superintendente de la Real Hacienda Jorge de Escobedo y finalizar el proceso de elección de los diputados a través de sus expedientes mediante el uso de las herramientas diplomáticas.

\section{LOS DISPOSITIVOS LEGALES SOBRE MINERÍA ANTES DEL TRIBUNAL}

Durante el siglo XVI el descubrimiento de las minas tanto en México y Perú y la exportación de los minerales representaron para España casi el ochenta por ciento de sus ingresos a las arcas del tesoro real para el sustento de la monarquía. El crecimiento de la actividad minera en el Perú se expandió gracias al hallazgo del mercurio y al empleo de la técnica de amalgamación que permitió un fuerte incremento de las exportaciones de remesas de plata.

La monarquía española contaba con un grupo de dispositivos con los cuales había logrado reglamentar lo concerniente a la minería en sus territorios como la Ley I, leyes 47 y 48, Título 32 del Ordenamiento de Alcalá y Cortes en la que se 


\section{Giovanna Valencia Álvarez \\ ELECCIÓN DE LOS DiPUTADOS TERRITORIALES DE MINERÍA}

dispuso el derecho de los Reyes en las minas de oro, plata y otros metales y la prohibición de explotarlas sin su licencia "todas las mineras de plata y oro y plomo y de otro qualquier metal de qualquier cosa que sea, en nuestro señorio real pertenecen a nos, por ende ninguno sea osado de las labrar sin nuestra especial licencia y mandado" ${ }^{1}$.

Desde 1542 en el Perú se comenzó a explotar el oro en las zonas de Carabaya, Oruro y Asillo y posteriormente se inició con la extracción de la plata que afloró por diferentes zonas del virreinato, lográndose altos índices de extracción y remisión a la hacienda española. Una de las zonas donde más se extrajo este mineral argentífero fue la ciudad de Potosí hoy ubicada en el estado de Bolivia llegando a ser considerada "la región de la plata",

En cuanto a la legislación minera para el virreinato peruano se comenzó desde temprano, entre 1536 y 1539, con el virrey Antonio de Mendoza ampliándose con las ordenanzas de 1550 que elaboró La Gasca y que fueron confirmadas por la Real Audiencia. No obstante uno de los verdaderos organizadores de la minería peruana fue el virrey Francisco de Toledo, quien instauró la mita minera, coincidiendo con el descubrimiento del mercurio que hasta ese momento se importaba desde España, lo que elevaba el precio del metal.

En febrero de 1574 mandó promulgar las Ordenanzas de Minas las que se hicieron extensivas para Chile y para el territorio argentino. Estuvieron divididas en 10 títulos y 90 ordenanzas, de las cuales en el Título VIII se estableció que era el alcalde mayor el encargado de ver en "la determinación de los pleitos y en las apelaciones y ejecuciones de las sentencias”3.

El rey Felipe II, hacia 1584, aprobó las ordenanzas del Nuevo Cuaderno ${ }^{4}$ las que fueron aplicadas en Indias mediante la Real Cédula de 1602 y posteriormente incorporadas en la Recopilación de Leyes de Indias de 1680; en la Ordenanza 77 del Nuevo Cuaderno se estipulaba la participación de un “Administrador General y uno de partidos 5”, además se normó todo lo relativo al “descubrimiento, labor y

\footnotetext{
${ }^{1}$ Novísima Recopilación de las Leyes de Indias, Madrid, 1805, p. 366, libro 2.

2 J. PÉREZ SÁENZ, “La minería colonial americana bajo la dominación española”, Boletín Millares Carlo, 7-8 (1985), p. 59.

3 J. BALDEÓN RÍOS, Apuntes del Derecho Minero Peruano [recurso electrónico], $<$ http://www.ilustrados.com/.../apuntes-historia-derecho-peruano.htm...> [consultado: 05.11.2011].

${ }^{4}$ Estas ordenanzas serán tratadas en los Comentarios que realizó Francisco Xavier de Gamboa.

${ }^{5}$ M. MOLINA MARTÍNEZ, Legislación Minera Colonial en Tiempos de Felipe II [recurso electrónico], <http://www.americanistas.es/biblo/textos/08/08-069.pdf> [consultado: 02.02.2012].
} 
beneficio de las minas de oro y plata, azogue y otros metales”, ${ }^{6}$ además de otras disposiciones entre las que destacan: la libertad de buscar minas en terrenos públicos y privados, el registro ante la justicia de minas y escribano, la creación de las minas de compañía y los tributos para la corona en oro y plata. En el libro $4^{\circ}$ Títulos 19 al 25 de la Recopilación se reconoció el derecho a las minas tanto de los españoles como de los indios, se estableció la autoridad de minas y se fijó los derechos de la corona con el quinto real.

Hacia 1761 se retomó el análisis a las Ordenanzas del Nuevo Cuaderno por el jurista Francisco Xavier de Gamboa mediante su obra titulada "Comentarios a las Ordenanzas de Minas”, obra de gran magnitud porque mostró la importancia de ese instrumento legal que permitió reglamentar, durante casi dos siglos, todo lo relativo a la minería; al mismo tiempo que se pudo adecuar a la realidad de los diferentes territorios que tuvo la monarquía española.

Los temas tratados en los Comentarios son variados se puede destacar lo referente a la propiedad de las minas y a los litigios sobre el derecho a ellas, las obligaciones que tenían los mineros con la Corona entre otros. Sobre los litigios mineros, el autor comenta que estos derechos fueron conferidos a los administradores de los asientos con la inhibición de las demás justicias, otorgándoles toda la jurisdicción en materia minera inclusive los casos civiles y criminales como autoridades de primera instancia.

En el Capitulo V relativo al registro de las minas de oro y plata, se incluye la Ordenanza XVII mediante la cual se señala lo siguiente. “qualquier que descubriere mina (...) dentro de veinte días despues que huviere descubierto o hallado el metal, sea obligado de la registrar ante la Justicia de Minas (...) y por ante escribano (...) y en el registro se declare la persona que la descubrió y registró (...) y que dentro de otros sesenta días después de hecho el tal registro (...) sea obligado de embiar y embie un traslado autorizado de el dicho registro ante nuestro administrador general" ${ }^{7}$; del mismo modo en la Ordenanza XIX se apunta que "los administradores de minas de cada partido tengan libro, donde se asienten todos los registros y que luego la envíen a la Contaduría Mayor y posteriormente se realice la misma labor cada seis meses de tal forma que se vaya actualizando

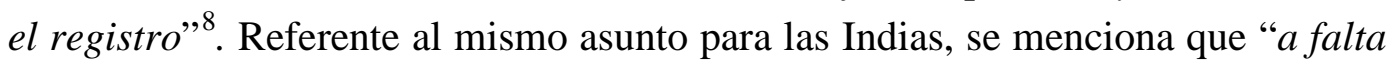
de administradores estarán los gobernadores, alcaldes mayores y escribanos de

\footnotetext{
${ }^{6}$ L. RODRÍGUEZ ENNES, “Minería romana, minería castellana, minería de la América colonial española: historia de un tracto sucesivo”, AFDUDC, 10 (2006), pp. 1006-1007.

${ }^{7}$ F. X. de GAMBOA, Comentarios a las Ordenanzas de Minas 1761, México, 1986, p. 100.

${ }^{8}$ F. X. de GAMBOA, Comentarios a las Ordenanzas..., p. 101.
} 
minas entre otros que se encarguen del registro" "9 y en el caso del Perú se retoma las Ordenanzas de Toledo quien proponía que "en cada provincia aya un escrivano de minas, ante el qual pasen todos, los registros y resida en el asiento principal (...) y que tenga todos los registros juntos y con claridad"10.

Es evidente la preocupación que se tuvo por reglamentar lo relacionado a la minería, hecho que se intensificó en el siglo XVIII con la fundación en 1779 de una “Academia y Escuela Teórica y Práctica de Metalurgia”"11 en Potosí, dedicada a la formación de los mineros en las técnicas empleadas en el laboreo, sin embargo será en México donde se inicie la organización de la actividad minera mediante el establecimiento de un tribunal, un colegio y un banco encargado de prestar auxilio a los mineros.

\section{EL TRIBUNAL DE MINERÍA Y LAS DECLARACIONES DE ES- COBEDO}

El siglo XVIII fue un período de cambios para el virreinato peruano porque se habían establecido las Intendencias y perdido el territorio del Alto Perú por la creación del virreinato de Río de la Plata; además el territorio había recibido la Visita General de Antonio de Areche.

A ello se sumó la disminución de la producción minera, a pesar del descubrimiento de nuevas vetas, ante esto el monarca español decidió impulsar la empresa minera a través de una serie de dispositivos legales.

Las reformas se emprendieron desde el virreinato de Nueva España, donde en 1783 el rey Carlos III mandó a promulgar las Ordenanzas de Minería, las mismas que dos años después mediante una Real Orden del 8 de diciembre, se hicieron extensivas para el Perú, de esta forma lo expresó en sus memorias el virrey Teodoro de Croix “así es que en los últimos años de su gloriosísima vida mandó el rey Carlos III (...) que se extendiesen a este reyno aquellas ordenanzas y que se guardase la misma práctica que en Nueva España (...)”"12;Jorge de Escobedo, visitador y posterior Superintendente de la Real Hacienda, se encargó de divulgar “las Ordenanzas para la Dirección, Régimen y Gobierno del Cuerpo de Mine-

\footnotetext{
${ }^{9}$ F. X. de GAMBOA, Comentarios a las Ordenanzas..., p. 104.

${ }^{10}$ F. X. de GAMBOA, Comentarios a las Ordenanzas..., p. 106.

${ }^{11}$ L. RODRÍGUEZ ENNES, “Minería romana, minería castellana...”, p. 1003.

${ }^{12}$ T. de CROIX, Memoria de los Virreyes que han Gobernado el Perú, Lima, 1859, tomo V, pp. 362-363.
} 


\section{Giovanna Valencia Álvarez \\ ELECCIÓN DE LOS DipUTADOS TERRITORIALES DE MiNERÍA}

ría”13 y con apoyo del virrey Croix se decidió aplicarlas con el afán de mejorar la situación económica y aumentar los ingresos a las arcas fiscales.

No obstante el clima entre estos dos personajes no fue del todo tranquilo porque a Escobedo se le otorgó el poder sobre lo relacionado a la minería y se le concedió "las facultades y privativo conocimiento en esta materia, al tiempo que se ponía coto a las intervenciones del virrey”" ${ }^{14}$; por esta razón Croix debió derogar los nombramientos de directores que había realizado en José Coquet y en Santiago Urquizu, quienes pasaron a estar bajo las órdenes del superintendente a quien debían de entregar un informe detallado de todo lo referente al establecimiento del tribunal.

El poder obtenido por éste no le hizo perder la brújula sobre lo que era su máxima preocupación adecuar las ordenanzas de Nueva España al Perú ${ }^{15}$, asumiendo la función de preparar un documento que reuniera esas modificatorias, las denominadas 56 Declaraciones, con ellas procuraba darle más poder a la superintendencia en detrimento de la autoridad virreinal; entre las más importantes se puede mencionar la Declaración 7, en la que se estipuló que la elección de los diputados generales "se tendrán ahora en la casa de esta Superintendencia, mientras la tiene propia el Tribunal"16; haciendo prevalecer la autoridad que tenía sobre el virrey; lo que se reafirma en la Declaración 9 por la cual los escrutinios además de tener la venia del virrey debían de ser comunicados, con las mismas formalidades, al superintendente "a quien Su Majestad tiene especialmente confiados los asuntos de minería como tan conexos con los del gobierno y arreglo de su real erario"17; con el poder obtenido pudo organizar la primera elección de Administrador y Diputados Generales, que en definitiva fue una de las más importantes por ser la primera y la única encabezada por él ${ }^{18}$.

${ }^{13}$ R. VARGAS UGARTE, Historia General del Perú. Postrimerías del poder español (17761815), Lima, 1966, tomo V, p. 80.

${ }^{14}$ M. MOLINA MARTÍNEZ, El Real Tribunal de Minería de Lima (1785-1821), Sevilla, 1986, p. 97.

${ }^{15}$ AGN (Archivo General de la Nación), TM (Tribunal de Minería), leg. 13, doc. 20, ff. 5-5v, 27. FEB. 1787. "Testimonio de la orden del Superintendente a los Ministros de la Real Hacienda donde los insta a adaptar e instalar en la minería del Perú la Real Ordenanza de México y que se establezca en Lima, el tribunal, los juzgados de alzadas y las diputaciones territoriales”.

${ }^{16}$ Ordenanzas de Minería y Colección de las Órdenes y Decretos de esta materia posteriores a su publicación, París, 1870, p. IX.

${ }^{17}$ Ordenanzas de Minería..., p. X.

${ }^{18}$ En la obra mencionada de Miguel Molina se mencionan 9 de los procesos electorales más importantes (1791, 1794, 1797, 1800, 1803, 1806, 1809, 1812 y 1815) y uno (1789) suspendido (pp. 188-211). 
Otras modificaciones relevantes a la Ordenanza de Nueva España fueron por ejemplo- la Declaración 30 en la que se indica que debido a la escasez de fondos se debía restringir el nombramiento de personal y establecer una escala de sueldos para los empleados ${ }^{19}$, así lo informó Escobedo al Tribunal de Minería advirtiendo además que se debía prohibir "el aumento de empleados y sueldos y en especial el de ensayador de minas que tiene un sueldo de 600 pesos que tampoco está contenido en el plan de dotaciones y solo está conforme al art. 37 del titulo $3{ }^{\text {20 }}$.

La Declaración 42 advierte sobre la retribución que debían efectuar los mineros para el sustento del tribunal detallándose que "en lugar de los dos tercios de real por marco, que el Artículo $1^{\circ}$, Título 16 de la mencionada Ordenanza concede al real Tribunal de Mejico para su dotación y gastos sobre todas las platas (...) contribuyan todos los mineros (...) con un real de esa moneda por cada marco, en la propia forma, y bajo las reglas prescritas" ${ }^{21}$.

De esta manera se buscaba que los ingresos percibidos fueran destinados, como lo indicaba la Ordenanza y lo mantuvo Escobedo en las Declaraciones 49 y 52 a la creación de un "banco general de rescates"22 y a la fundación de un colegio para la instrucción de especialistas en mineralogía ${ }^{23}$.

Con estas modificatorias se aspiraba regularizar la administración de la minería para que las recaudaciones de metales fueran más productivas y que llegarán mayores remesas a España, es por ello que cuando se establecieron las autoridades del Tribunal en Lima se inició el proceso de formación de las diputaciones territoriales de las cuales debían reunir información relacionada con "el número de minas (...) el tipo de maquinaria que se usaba, el número de plantas de beneficio ${ }^{24,}$ y otros temas de interés, de ahí que las personas que representaban a las diputaciones y que eran elegidas debían de participar en un proceso de elección transparente en cumplimiento a los procedimientos señalados en las Ordenanzas para evitar una mala administración.

\footnotetext{
${ }^{19}$ Ordenanzas de Minería..., p. XXI.

${ }^{20}$ AGN, TM, leg. 13, doc. 23, 26. ENE. 1787.

${ }^{21}$ Ordenanzas de Minería..., p. III.

${ }^{22}$ Ordenanzas de Minería..., p. XXXV.

${ }^{23}$ AGN, TM, leg. 13, doc. 24. 31. MAY. 1785 “Oficio dirigido por Jorge Escobedo al Superior Gobierno mediante el cual remite el testimonio del expediente sobre la constitución del colegio o seminario de minería por Jose Coquet y Santiago Urquizo, mediante la elaboración de un plan o proyecto y (...) la edificación del edificio del colegio, las oficinas y manutención de los discípulos y maestros”.

${ }^{24}$ J. FISCHER, Minas y Mineros en el Perú colonial 1776-1824, Lima, 1977, p. 76.
} 


\section{LA ELECCIÓN DE LOS DIPUTADOS A TRAVÉS DE SUS EXPE- DIENTES}

La Diputación Territorial, parte integrante de la administración minera, ejerció funciones de gobierno y de justicia con carácter autónomo en relación al Tribunal de Minería al que sólo se podía apelar en casos de sentencia definitoria ${ }^{25}$, pero mediante una Real Orden del 12 de febrero de 1797 se debilitó a las diputaciones al impedirles "a los diputados locales ejercer su derecho exclusivo de juzgar casos en primera instancia ${ }^{26}$, , otorgándole al Tribunal mayores atribuciones como instancia de apelación lo que a pesar de las continuas quejas de los diputados de Huarochirí, Cailloma y Hualgayoc terminó siendo confirmado en 1804 por un Superior Decreto del virrey Marques de Avilés.

Una de las funciones más importantes del Tribunal fue el registro de los mineros con este mecanismo se controlaba el pago de la renta y se habilitaba a los mineros para que puedan ser elegidos como jueces o diputados de los asientos o diputaciones; en el Titulo 2, Artículo 2 de la Ordenanza se menciona que serán matriculados "asentándolos por sus nombres en el libro de matrículas que deberán tener el Juez y Escribano de aquella minería (...). Todos los que hubieran trabajado más de un año una o muchas minas, expendiendo como dueños de ellas en todo, o en parte, su caudal, su industria, o personal diligencia y afán serán matriculados por tales mineros de aquel lugar ${ }^{27}$ ". En la Declaración 12 se añade que debían "matricularse en el real o asiento de minas más inmediato en que las haya, de modo que formándose (...) el libro de la matricula comprenda está los demás mineros esparcidos de aquel distrito, para que todos compongan el gremio que ha de reconocer por su cabeza territorial la diputación ${ }^{28, "}$.

Justamente hacia 1788 los mineros de Ica solicitaron que el Tribunal les conceda el permiso para crear una nueva diputación territorial debido a que por razones perjudiciales afectaba a su gremio para lo cual sostienen que es su "intento demostrar a vuestra señoria lo importante que es la diputacion en esta provincia los agravios que reciben los mineros con la falta de ella: la ventaja a favor del cuerpo de mineria por su continuado trabajo (...) y pedir se traiga a la vista el mismo codigo de mineria que sera el mas precioso apoyo de nuestra solicitud en

\footnotetext{
${ }^{25}$ Ordenanzas de Minería..., pp. 48-51, título 3, artículos 4, 7 y 9.

${ }^{26}$ J. FISCHER, Minas y Mineros en el Perú colonial..., p. 112.

${ }^{27}$ Ordenanzas de Minería..., pp. 34-35.

${ }^{28}$ Ordenanzas de Minería..., p. XI.
} 
todas sus partes al tiempo que se examine el expediente de su asumpto ${ }^{29, .}$. Esta modificatoria era indispensable debido a que los escrutinios para la elección de diputados se efectuaban en los asientos mineros reconocidos, y no precisamente en las zonas donde existían minas, de ahí la necesidad de agruparlas para una mejor administración por parte de las autoridades.

Para el presente trabajo se han analizado los expedientes del fondo "Tribunal de Minería” del Archivo General de la Nación correspondientes al período de 1785 a 1821. El objetivo de este análisis es exponer las diferentes etapas del proceso de elección teniendo en cuenta las Ordenanzas y la adaptación que realiza Escobedo para el Perú.

La convocatoria para la elección de diputados empezaba los primeros días del mes de enero así lo reglamentó el Título II, artículo 3 de las Ordenanzas la que se daba a conocer mediante la publicación de un bando en los pueblos que debían acudir a los escrutinios-por ejemplo-en la diputación de Lucanas el gobernador hizo "saber al publico e individuos del real cuerpo de mineria que en el proximo dia primero de enero se ha de celebrar la junta prevenida por reales ordenanzas para la eleccion de diputado (...) para cuio efecto y la concurrencia de dichos vocales por si o por medio de sus poderes se publique este por bando con advertencia que se han de hallar en este pueblo con quatro dias de anticipasion a dicha eleccion para verificar los escrutinios prevenidos por dicha real ordenanza sin que se les permita a los vocales tener mas poder que uno (...) todo lo qual se pu-

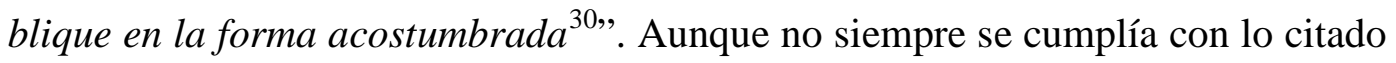
en la norma como lo sucedido en 1811 en Lucanas y que fue observado por los diputados territoriales debido a que "por varios motivos se omitio la eleccion que debio haverse practicado el $1^{\circ}$ de enero pasado y haviendo practicadose el dia 12 de maio sin guardar el debido orden de la real ordenanza, sin aquellos requisitos de convocatoria que en otras ocaciones se han tirado, (...) declarandola por nula por los vicios que se halla revestida (...) y para proceder a la nueva eleccion que se ordena mandamos fixar carteles para proceder nuevamente a la eleccion que se debe hacer de la fecha en 30 dias en cuio termino podran volver las contestaciones de los partidos a donde presisamente se han de despachar copias de esta convocatoria con el oficio de estilo a los señores governadores y subdelegados de ellos a fin de que los mandasen fixar en las casas de sus partidos para que llegue a noticia de todos los gremiantes que componen el cuerpo ${ }^{31, "}$

\footnotetext{
${ }^{29}$ AGN, TM, leg. 19, doc. 7, 28. MAR. 1788, fol. 1-2.

${ }^{30}$ AGN, TM, leg. 16, doc. 28, 28. NOV. 1795, ff. 2-2v.

${ }^{31}$ AGN, TM, leg. 23, doc. 15, 04. AGO. 1811, ff. 1-1v.
} 


\section{Giovanna Valencia Álvarez \\ ELECCIÓN DE LOS DipUTADOS TERRITORIALES DE MiNERÍA}

La Declaración 13, a diferencia de lo que se indicaba en el Artículo 7, Título $\mathrm{II}^{32}$, advertía que la elección debía tener como asistente y testigo imparcial al Subdelegado del Partido, quien en representación del Gobernador Intendente, de-

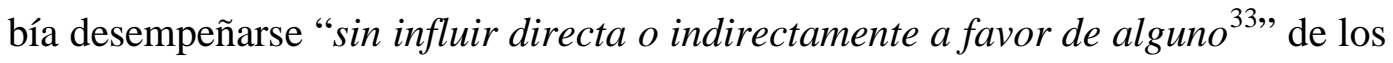
candidatos con lo cual se le otorgaba legalidad al acto en algunas ocasiones estos funcionarios tuvieron que nombrar a otras personas para evitar el retraso y perjuicio que pudiera ocasionar su alejamiento en la elección. El subdelegado de Cho$\mathrm{ta}^{34}$ realizó una consulta al Tribunal para que se le permitiera comisionar un sujeto que presida el sufragio, con la finalidad de evitar la desnaturalización del proceso, obteniendo una respuesta afirmativa de parte del Director quien aprobó lo solicitado por el subdelegado, permitiendo el normal desarrollo las elecciones.

Una vez que se comunicaba sobre el inicio de las elecciones se notificaba a los mineros de los diferentes centros poblados para que asistieran a la diputación y se eligieran a los diputados y sustitutos. Para el aviso a los mineros se recurrió al pregón en momentos en que las personas pudieran tomar conocimiento del acto

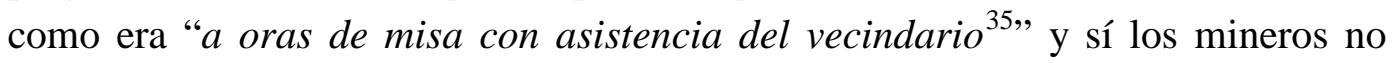
podían concurrir, por la distancia, por dolencias físicas o por recarga de labores tuvieron la facultad de otorgar un poder a favor de un representante que emitiría su voto como si estuviese presente, así ocurrió en 1809 en el nombramiento de diputado general $^{36}$ en el que los apoderados presentaron ante el Tribunal una copia de los poderes conferidos ${ }^{37}$ para que fueran aprobados y que con ello se celebrase la elección.

De acuerdo a lo estipulado en la Ordenanza en el Título II, Artículos 8 y 9 se debían de elegir dos diputados y cuatro sustitutos por un período de dos años, de los cuales cada año debía ser sustituido el más antiguo y reemplazado por el que hubiese obtenido mayor cantidad de votos en la elección anterior para lo cual se debía tener en cuenta a hombres instruidos en la materia "practicos e inteligen-

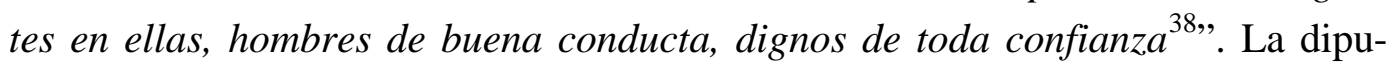
tación de Huarochirí mediante un oficio dirigido al Tribunal recomendaba que

\footnotetext{
32 Ordenanzas de Minería..., p. 36: "El Juez de Minas de cada Real o Asiento, y los Diputados del año anterior, presidirán y ordenarán la elección”.

${ }^{33}$ Ordenanzas de Minería..., p. XII.

${ }^{34}$ AGN, TM, leg 43, doc. 24, 17. NOV.1790, ff. 1-1v.

${ }^{35}$ AGN, TM, leg. 16, doc. 28, 13. DIC.1795, f. 7.

${ }^{36}$ AGN, TM, leg. 7, doc. 61, 27. DIC.1809.

${ }^{37}$ Ordenanzas de Minería..., p. 36, título II, artículo 6: “Los Administradores de Minas podrán votar en lugar de sus Amos no siendo estos vecinos de aquel territorio, y teniendo para ello poder bastante".

${ }^{38}$ Ordenanzas de Minería..., p. 35.
} 


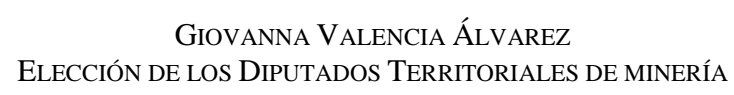

para la elección de diputados, los candidatos debían de cumplir con determinadas características como ser "sugetos idoneos tanto por su nacimiento como de mineros practicos y de buen proceder y no hallarse impedidos por no haver pasado el tiempo prefinido por ordenanza en caso de haver obtenido alguno de los empleos de la diputacion ${ }^{39,}$.

La elección se materializaba en el Acta ${ }^{40}$ documento en el cual se evidenciaba el voto emitido por los mineros participantes o sus poderdantes así como sus rúbricas al final del documento en señal de conformidad. Una vez culminado este procedimiento el acta se incorporaba al expediente, fue una práctica que se insertará un testimonio o una copia fiel del original y que fuera encabezada por el nombre del asiento, la fecha y la autoridad que presidía la junta; luego la diputación pedía la aprobación al Tribunal quien a su vez solicitaba una opinión del Director para ratificar la elección en cumplimiento a lo ordenado en los dispositivos legales ${ }^{41}$.

Era frecuente que la diputación se comunicará con el tribunal a través de un oficio en el cual exponía lo acontecido en el escrutinio -como ejemplo- tenemos el documento con el que se dirigió el Real de Minas de Huallanca expresando lo siguiente: "dirijimos a vuestra señoria en copia certificada la acta y votacion celebrada en esta territorial el dia primero del presente mes para que se digne darle

${ }^{39}$ AGN, TM, leg. 2, doc. 78, 20. DIC. 1795, ff. 2-2v.

${ }^{40}$ AGN, TM, leg. 2, doc. 105, ff. 2-2v. "En el asiento mineral de San Antonio de Yauli provincia de Huarochiri a ocho dias del mes de enero de mil ochocientos quince hante nos don Bernardo de Urizar presidente comisionado por el señor gobernador de esta provincia y don Manual Barbado diputado de mineria de este partido en virtud de la convocatoria de estilo que precedió se congregaron los mineros del gremio en numero de nuebe vocales para nombrar un diputado y un sustituto conforme a lo prevenido en el articulo 8 y 9 del titulo 2 de las reales ordenanzas de mineria se leyeron los articulos de las ordenanzas concernientes al caso y habiendo hecho el escrutinio procedieron a la eleccion exibiendo cada uno de los vocales su voto para uno y otro empleo segun estilo y salio electo diputado don Francisco Cayro a pluralidad de votos igualmente salio electo de sostituto don Esteban Albarez por dos votos don Jose Maria por dos votos y don Fermin Ymaña por otros dos y los tres restantes se dividieron en don Jose de la Canal don Angel Landa y don Sebastian Aranguez habiendo recaido el voto del señor presidente en don Esteban Alvarez con el cual quedo electo sostituto y se concluyo la elección no habiendo dicho que le irrite quedaron electos don Francisco Cayro diputado y don Esteban Alvarez sustituto quienes juraron a Dios nuestro señor y una señal de cruz [SIGNO DE LA CRUZ] ejercer fiel y legalmente sus respectivos empleos y todos los demas concurrentes y vocales prestaron el correspondiente obedecimiento y yo el espresado don Bernardo de Urizar presidente comisionado para la predicha junta certifico que conozco a los mineros que la compusieron y que todo por el como va expresado y en su virtud lo firmaron”.

${ }^{41}$ Ordenanzas de Minería..., título II, artículo 14, p. 43: “Hecha la elección, darán cuenta y noticia de ella inmediatamente al Real Tribunal General de Minería para que, no conteniendo alguna nulidad o vicio cierto y calificado, obtenga la aprobación del Superior Gobierno”. 


\section{Giovanna Valencia Álvarez \\ ELECCIÓN DE LOS DipUtAdos TERRITORIALES DE MiNERÍA}

el curso que meresca y obtenga la superior aprobación ${ }^{42 "}$. Algo poco usual era que se insertará el original del acta, lo que sí ocurrió en la elección de diputados de Lucanas en 1811, de este modo lo advirtió el Subdelegado "por concluidas estas diligencias remitanse originales al Real Tribunal General de Mineria con el oficio de estilo y dando testimonio de todo para devida constancia ${ }^{43}$ ".

No cabe duda que la información proporcionada en este tipo de documento servía para que el tribunal estuviese al tanto de alguna anomalía que se hubiese suscitado en las elecciones y que hubiese podido cambiar el curso de los resultados, así lo anotaron en dos oportunidades diferentes en la diputación de Lucanas tanto en 1796 cuando el gobernador remite el acta e informa que la elección no se ha practicado como lo previene la ordenanza debido a circunstancias de la naturaleza "no habiendose verificado la junta en el dia primero de enero segun la convocatoria a causa de que las exesivas aguas retardaron a los vocales y sus poderes $^{44, "}$, así como en la elección de 1800 en la cual se alude que se hizo en una

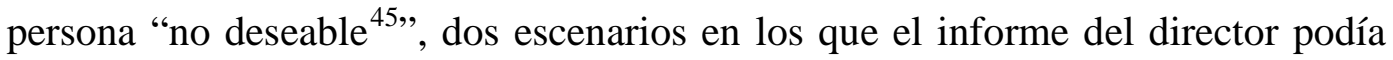
omitir una opinión a favor o en contra de los resultados.

Una vez recibido el documento por el Tribunal este solicitaba la aprobación al Director mediante una anotación al margen izquierdo para que informe ${ }^{46}$ si el acto de elección se había realizado con normalidad y en cumplimiento a las ordenanzas o en caso contrario declararlo nulo por la inobservancia de las normas vigentes. Tal es el caso de la elección efectuada en el Real de Minas de Lircay en la que Manuel de Villalta, director general, informa que después de haber examinado el acta "halla arreglada a ordenanza la eleccion de diputado y sustitutos de mineria (...) en el presente año por lo que podra vuestras señorias elevarla a la superioridad con el oficio de estilo para su aprobación ${ }^{47,}$, del mismo modo en el informe que se elaboró para las elecciones de la diputación de Curahuasi el director "dice que no le ocurre razon alguna por donde pueda presumirse vicio o nulidad en los nombramientos (...) en cuya virtud podra vuestra señoria impetrar de

${ }^{42}$ AGN, TM, leg. 22, doc. 18, 1805, f. 4.

${ }^{43}$ AGN, TM, leg. 23, doc. 15, 04. SET. 1811, f. 4v.

${ }^{44}$ AGN, TM, leg. 16, doc. 28, 23. ENE. 1796, f. 27.

${ }^{45}$ AGN, TM, leg. 16, doc. 34, 23. ENE. 1800, ff. 6 y 7v.

${ }^{46}$ AGN, TM, leg. 11, doc. 25, f. 5 "[Al margen: 25 enero 1811. Por recibido con la acta que se acompaña y pase al señor Director General. Rúbricas de miembros del Tribunal. Refrendado por el secretario]".

${ }^{47}$ AGN, TM, leg. 11, doc. 25. ENE. 1811, f. 5v. 
su excelencia su superior aprobacion de dichas elecciones con arreglo a lo dispuesto por Su Magestad al articulo 14 del titulo 2 de la real ordenanza ${ }^{48, "}$

Sin duda el Informe emitido por el director debía ser lo bastante consistente y minucioso al analizar el acto en sí de la elección, sin embargo mientras no se trasgrediesen los preceptos establecidos el expediente podía continuar con el tratamiento administrativo correspondiente así se demuestra en un extenso informe que se emitió para la elección de diputados de Lucanas en 1796 y que a continuación se presenta: “el Director (...) dice que el principal instituto de el tribunal es la verdad sabida y la buena fe guardada. Por la acta remitida se conoce que los sufragios de los mineros recayeron en don Miguel de Echenique (...) en cuya virtud es necesario sostener el nombramiento pidiendo la superior aprobacion de su excelencia sin dejar por eso de individualizar los defectos de las actas y de que fue autora la direccion del subdelegado. Este conboco por si solo al gremio segun los carteles que libro fijar (...) sin distinguir de tiempos y circunstancias equiboco los años de 94 y 96 sin considerar que en el primero fue por la superioridad cometida a los subdelegados la convocatoria para formalizar el establecimiento para cuyo efecto fue especialmente comisionado su excelencia por el Rey creyo que el de 96 establecido el tribunal perfectamente hubiese de ser lo mismo que en el de 94 sin atender a que ceso el motivo y las cosas deben tomar su orden regular. Los jueces reales no tienen otra facultad e intervencion en esta linea que la que les señala el articulo 7 de el titulo 1 que es presidir y ordenar la eleccion en consorcio de los diputados. Estos fueron demasiado deviles en permitir al subdelegado esa fijacion de carteles como si fuese una subasta publica o como si faltasen otros arbitrios mas decorosos y decentes para un gremio pero ya que dichos diputados no se opusiere a una citacion tan poco respetuosa debieron subscribir los carteles. En estos se previene concurran los vocales quatro dias antes de la eleccion para que se berifiquen los escrutinios dispuestos por ordenanza. No se halla articulo alguno que mande tales escrutinios para eleccion de diputados territoriales y solo si para los ministros de el tribunal articulo 8 titulo 1 y que no se dispensaron en los proximos nombramientos sino que los tres diferentes dias prevenidos en el articulo citado se suplieron con tres distintas juntas para no propasar el 31 de diciembre en que ha de hacerse la eleccion segun el articulo 9 esta corta digresion es oportuna para el subdelegado. En dicho cartel se halla igualmente el vicio de permitir a los vocales el sufragio por poder en que se procedio contra lo prevenido en la circular de 7 de noviembre y contra lo espresamente

\footnotetext{
${ }^{48}$ AGN, TM, leg. 37, doc, 11, 20. FEB. 1789, f. 4v.
} 


\section{Giovanna Valencia Álvarez \\ ELECCIÓN DE LOS DipUTADOS TERRITORIALES DE MiNERÍA}

mandado en el articulo 6 titulo 2 por el que solo los administradores de minas y no otros pueden votar a nombre de sus amos si estos no fuesen vecinos del territorio en donde se hace la eleccion sin embargo en la de Lucanas por disposicion del subdelegado se encuentra 15 poderes de fojas 8 a 22 y sin que los apoderados tengan la calidad de administradores. Con principios tan defectuosos se paso al auto de fojas 23 despues de haverse leido en el conclave desde el articulo 1 al 7 del citado titulo calificaron poderes y se paso a los vocales una lista en que se contenian 9 candidatos de entre quienes devia resultar el diputado ique procedimiento tan abusivo tan voluntarioso e inductivo de coaccion, ello no lo autoriza la ordenanza menos falta regla porque es bien expresiva en el codigo con que no hay mas sino hacer cada uno lo que quiere (...) mas nada puede obrar la aprobacion que debe solicitarse estando descubierta la voluntad de los mineros optada la superior aprobacion le parece al director se pase a la diputacion copia testimoniada con insercion de este dictamen y el oficio que corresponde del tribunal enunciatibo de los vicios opuestos y reprehensibo de la conducta que ha manifestado aquel capitulo ${ }^{49,}$.

Como se puede examinar en este caso el informe del director hace notar los errores cometidos en el proceso de elección, no obstante ello no invalida la designación de la persona aunque si lo considera importante de señalar para que en lo sucesivo no se cometan las mismas faltas. Precisamente por ello se debía ser cuidadoso antes de pedir la aprobación al Superior Gobierno y pasar el expediente a su despacho, en alguno de ellos se encuentran opiniones para que las elecciones sean revisadas o en su defecto revocadas, como el informe que se expuso en la elección de diputados de Lucanas en el cual se encuentran vicios y debe ser declarada nula por lo que "debe devolverse (...) para que se reaga y enmiende sin pasar el expediente a la Superioridad porque (...) compromete al tribunal para que solisite la superior aprobacion quando el nombramiento no contiene defecto substancial pero conteniendolo el tribunal deve procurar el remedio por si y por su autoridad que es independiente en este caso sobretodo vuestra señoria resolbera lo que fuere de su agrado ${ }^{50,}$.

Asimismo el director podía disponer que en caso las elecciones no se hubiesen desarrollado se celebrasen en un plazo mínimo como ocurrió en 1811 en Huamanga donde los mineros se encontraban ocupados en las labores propias de su oficio a lo que se opinó que "no siendo este un justo motivo para contravenir a

\footnotetext{
${ }^{49}$ AGN, TM, leg. 16, doc. 28, 12. FEB. 1796, ff. 27-28v.

${ }^{50}$ AGN, TM, leg. 16, doc. 14, 22. FEB. 1800, ff. 8v-9.
} 
los estatutos 3 y 8 del titulo 2 de nuestra ordenanza que previenen y mandan se haga eleccion de oficios (...) es de dictamen su ministerio se les contexte (...) que inmediatamente y sin perdida de tiempo verifiquen su convocatoria para la eleccion (...) a fin de no invertir el orden de nuestro codigo (...) cumplan con lo dispuesto en el art. 16 del citado titulo y practicando el informe que en el se ordena para que ilustrado este Tribunal (...) de su estado tome los medios y arvitrios oportunos para su fomento y prosperidad ${ }^{51,}$.

Posteriormente continuando con el trámite señalado una vez recibida la exposición del director, el Tribunal se encargaba de elevar todo el expediente al Superior Gobierno para su aprobación en concordancia con lo ordenado, a través de un Oficio que se encabezaba en la parte superior al centro con el crismón y con el tratamiento de cortesía establecido para dirigirse al virrey que era Excelentísimo Señor; el contenido del documento era lo bastante preciso debido a que se trataba de un acto de formalidad y en muy pocas ocasiones el virrey rechazaba a los diputados y sustitutos que habían sido elegidos.

En el siguiente documento se muestra lo sucinto y el uso de un lenguaje claro con el cual los miembros del Tribunal se dirigían al Superior Gobierno "traslado a las superiores manos de vuestra excelencia el expediente obrado para la eleccion de oficios de diputado y sustitutos de mineria del aciento de Lircay en el que se ha procedido conforme a ordenanza por lo que no encuentra embaraso para que recayga la superior aprobacion de vuestra excelencia ${ }^{52, "}$

Un caso singular fue la elección de 1789 en el asiento de Curahuasi, en ella el informe del director había sido favorable y no había encontrado vicio alguno, sin embargo al momento en el cual el tribunal se dirige al virrey le solicita que precise el cumplimiento de las disposiciones que para el Perú se habían reglamentado y el tenor es el siguiente: "por lo que siendo vuestra excelencia servido podra dispensarla advirtiendosele al juez real que precedio la junta que en las ulteriores a que concurra observe lo prevenido en la declaracion 16 que prescribe la forma en que debe darse cuenta de las elecciones firmandose la carta en que asi se avise por el juez real que haga de presidente por los diputados que acaban por los que nuevamente se elijan cuia formalidad se ha omitido en la presente ${ }^{53, ;}$ in duda lo que se buscaba era que se aplicaran correctamente las directivas y quien mejor que la máxima autoridad en el virreinato para hacérselo recordar a sus funcionarios.

\footnotetext{
${ }^{51}$ AGN, TM, leg. 23, doc. 15, 18. MAY. 1811, ff. 9-10v.

52 AGN, TM, leg. 11, doc. 25, 25. ENE. 1811, f. 6.

${ }^{53}$ AGN, TM, leg. 37, doc. 11, 05. MAR. 1789, f. 5.
} 


\section{Giovanna Valencia Álvarez \\ ELECCIÓN DE LOS DipUTADOS TERRITORIALES DE MiNERÍA}

Una vez que la Secretaría del Superior Gobierno tomaba conocimiento de esta elección despachaba con el Virrey la aprobación y su confirmación, lo que se podía evidenciar en una escritura al margen izquierdo del oficio, que simplificaba la respuesta en una sola frase “Apruébese y devuélvase " $^{54,}$, a este acto se le denominaba Superior Decreto y en la gran mayoría de expedientes consultados constaba de la rúbrica del virrey y del refrendo del secretario, aunque no faltaron ocasiones en las cuales el virrey además de su rúbrica firmaba con su apellido o con su título ${ }^{55}$.

En muy pocas ocasiones el virrey tuvo una participación notoria en este tipo de actos, no obstante uno de los casos más resaltantes fue el de la elección de diputados en Chota en la que a solicitud del subdelegado expidió un Superior Decreto por el cual advertía que no se debía alterar lo prescrito en las ordenanzas hasta que se aprobaran de manera definitiva las Declaraciones de Escobedo que eran una adaptación para el Perú y que todavía se debía de esperar la ratificación del Rey, por ello en 1794 emitió el siguiente decreto "teniendo presente que por el articulo 2 titulo 2 de la misma Real Ordenanza se determina expresamente que todos los que huvieren trabajado mas de un año o muchas minas expendiendo como dueños de ellas en todo orden parte su caudal su industria (...) sea matriculados por tales mineros formandoseles el asiento correspondiente en los terminos que en el se especifica previniendo en el articulo 3 del propio titulo que los expresados mineros asi matriculados concurran a sufragar en las elecciones de diputados en la junta que de ellos se ha resultar (...) y atendiendo a que por el articulo 6 se permite que los administradores de minas puedan votar en lugar de sus amos no siendo estos vecinos de aquel territorio con tal que para ello tengan poder bastante, se declara que los mineros en quienes concurran las circunstancias especificadas en el citado articulo 2 deven sufragar en las elecciones de diputados $^{56,}$.

El expediente concluía con un procedimiento que le correspondía al tribunal, debido a que una vez emitido el superior decreto éste lo recibía y daba cumplimiento a lo ordenado remitiendo con el oficio de estilo una copia del expediente y el original era guardado en el archivo. Generalmente este trámite se ponía por escrito al dorso de lo dispuesto por el virrey y tenía el siguiente tenor "por recivi-

${ }^{54}$ AGN, TM, leg. 16, docs.12, 33; leg. 11, doc. 25; leg. 2, doc. 78.

${ }^{55}$ AGN, TM, leg. 2, doc. 109, f. 5 "[Al margen] Lima, 31 de enero de 1818 . Apruebase la eleccion que se expresa y devuelvase para los efectos consiguientes. Pezuela [rubricado] Francisco de Montoya [rubricado] [refrendado por el secretario]".

${ }^{56}$ AGN, TM, leg. 72, doc. 13, 07. NOV. 1794, ff. 5-8. 


\section{Giovanna Valencia Álvarez \\ ELECCIÓN DE LOS DiPUTADOS TERRITORIALES DE MINERÍA}

do el superior decreto de su exelencia y para su cumplimiento saquese de el y del oficio que le antesede copia certificada y dirijase con el que corresponde a la diputacion territorial de Huallanca para su inteligenca y satisfacción ${ }^{57,}$, el mismo era rubricado por los miembros del tribunal y refrendado por el secretario.

El análisis externo del corpus documental conformado por los expedientes se caracteriza por encontrarse elaborados en papel de algodón con marcas de agua. Los expedientes consultados constan de una portada o caratula sin foliar y que podía obedecer a una funcionalidad archivística, debido a que aparecían los datos básicos del expediente: como el número, el año de inicio del procedimiento y el asunto.

Las copias o los testimonios insertados del acta o de las escrituras de poder estuvieron redactadas en papel sello tercero o cuarto debido a que se había establecido su uso para procesos administrativos o de oficio ${ }^{58}$ y con ello evitar la falsificación de los documentos ${ }^{59}$.

Hacia finales del siglo XVIII se continuó usando la tinta ferrogálica que en muy pocos casos ha corroído el papel, se empleó la letra humanística lo bastante comprensible y el uso del lenguaje era escueto y sencillo, no obstante hubo una recurrencia a las expresiones legales que iban a sustentar cada procedimiento.

De esta forma se ha visto de una manera panorámica uno de los procesos más importantes del Tribunal de Minería, con el cual también se intentaba que estas autoridades pusieran el énfasis para que se realizaran las actividades mineras bajo los parámetros establecidos en las Ordenanzas con la finalidad de incrementar los envíos de remesas de metales a España, este fue un intento de descentralizar el poder que tenía el tribunal en Lima para que los asientos mineros se pudieran manejar independientemente lo que paralelamente se iba a reforzar con el colegio de mineros y el banco de rescate sin embargo, los conflictos entre autoridades comenzando por el virrey y el superintendente al inicio del establecimiento del tribunal y los posteriores enfrentamientos entre los funcionarios y diputados

\footnotetext{
${ }^{57}$ AGN, TM, leg. 22, doc. 18, 1805, f. 5v.

${ }^{58}$ I. SECO CAMPOS. "La Provisión de Papel Sellado en América: comentario de unas cifras y la actividad burocrática indiana”, Boletín ANABAD, 4 (1994), pp. 109-126.

${ }^{59}$ Novísima Recopilación..., tomo V, libro X, título XXIV. Del uso del papel sellado en las escrituras, autos e instrumentos públicos. Ley I don Felipe IV Madrid 15.12.1636. pp. 149-150. "Habiendo reconocido los grandes daños que padece el bien publico y particular de mis vasallos con el uso de los instrumentos y escrituras falsas, cobrando fuerza este delito (...) mandamos, que de aquí adelante no se pueda hacer ni escribir ninguna escritura ni instrumento publico, ni otros despachos que por menor iran declarados (...) porque nuestra voluntad es añadir esta nueva solemnidad del sello por forma substancial, para que sin ella no puedan tener efecto ni valor alguno".
} 
territoriales no permitieron esta importante iniciativa, no se puede ni cualificar el rol que cumplieron las diputaciones y sus autoridades porque para cuando las aguas se habían logrado calmar comenzaba otra fase para el virreinato peruano aún más convulsionada el proceso independentista por ello que el tribunal tuvo muy poca influencia y lo que hubiera sido una buena política con dispositivos legales que los respaldaban termino quedando en el suspenso y con el tiempo desapareciendo definitivamente al quedar suprimido por una ley del 06 de febrero de $1875^{60}$.

${ }^{60}$ J. BALDEÓN RÍOS, Apuntes del Derecho Minero Peruano, p. 9. 


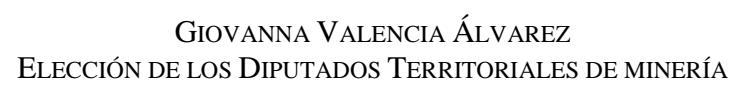

\section{BIBLIOGRAFÍA}

J. F. BALDEÓN, Apuntes del Derecho Minero Peruano [recurso electrónico], <http://www.ilustrados.com/.../apuntes-historia-derecho-peruano.htm...> [consultado: 05.11.2011].

C. CONTRERAS, "Transferencia de tecnologías e imperio. El caso de la minería andina en el siglo XVIII”, Diálogo Andino, 33 (2009), pp. 29-42.

T. CROIX, Memoria de los Virreyes que han gobernado el Perú, Lima, 1859, tomo $\mathrm{V}$.

C. DEUSTUA PIMENTEL, “Aspectos de la economía peruana a fines del siglo XVIII (1790-1796)”, Boletín del Instituto Riva Agüero, 1969-1971, pp. 135304.

A. DOUGNAC RODRÍGUEZ, "Proyección de las ordenanzas de minería de Nueva España en Chile (1787-1874)”, Revista de Estudios HistóricosJurídicos, XXI (1999), pp. 111-158.

A. DOUGNAC RODRÍGUEZ, "La real administración del importante cuerpo de minería de Chile (1787-1802)”, Revista chilena de historia del derecho, 8 (1981), pp. 109-130.

J. FISHER, Minas y Mineros en el Perú colonial 1776-1824, Lima, 1977.

E. FLORES CLAIR, "El colegio de minería: una institución ilustrada en el siglo XVIII Novohispano”, Estudios de Historia Novohispana, 20 (1999), pp. 3365.

F. X. GAMBOA, Comentarios a las Ordenanzas de Minas 1761, México, 1986.

J. A. GONZALES PEDRAZA, “Diplomática contemporánea aplicada a documentos de los siglos XIX y XX: los expedientes de concesiones mineras”, Documenta \& Instrumenta, 5 (2007), pp. 77-89.

M. MOLINA MARTÍNEZ, El Real Tribunal de Minería de Lima (1785-1821), Sevilla, 1986.

M. MOLINA MARTÍNEZ, Legislación Minera Colonial en Tiempos de Felipe II [recurso electrónico], <http://www.americanistas.es/biblo/tex-tos/08/08-069. pdf $>$ [consultado: 02.02.2012].

Novísima Recopilación de las Leyes de Indias, Madrid, 1805. 
Ordenanzas de Minería y Colección de las Órdenes y Decretos de esta materia posteriores a su publicación, París, 1870.

J. E. PÉREZ SÁENZ DE URTURI, “La minería colonial americana bajo la dominación española”, Boletín Millares Carlo, 7-8 (1985), p. 59.

Recopilación de Leyes de Indias [recurso electrónico], Archivo Digital del Congreso de la República del Perú, <http://www.congreso.gob.pe/ntley/ LeyIndiaP.htm> [consultado: 03.10.2011].

L. RODRÍGUEZ ENNES, “Minería romana, minería castellana, minería de la América colonial española: historia de un tracto sucesivo”, AFDUDC, 10 (2006).

I. SECO CAMPOS, “La Provisión de Papel Sellado en América: comentario de unas cifras y la actividad burocrática indiana”, Boletín ANABAD, 4 (1994), pp. 109-126.

R. VARGAS UGARTE, Historia General del Perú. Postrimerías del poder español (1776-1815), Lima, 1966, tomo V. 